\title{
Quantitative source apportionment of polycyclic aromatic compounds (PACs) in Athabasca oil sands region snowpack using compound-specific carbon and hydrogen isotope analysis
}

\author{
JASON M. E. AHAD ${ }^{1}$, HOOSHANG PAKDEL ${ }^{1}$, THIBAULT \\ LABARRE ${ }^{1}$, COLIN COOKE ${ }^{2,3}$, MARTINE M. SAVARD ${ }^{1}$ \\ AND PAUL R. GAMMON ${ }^{1}$ \\ ${ }^{1}$ Natural Resources Canada \\ ${ }^{2}$ Government of Alberta \\ ${ }^{3}$ University of Alberta \\ Presenting Author: jason.ahad@canada.ca
}

\begin{abstract}
A growing number of investigations in Canada's Athabasca oil sands region (AOSR) have revealed that petroleum coke (petcoke) - the carbonaceous by-product of bitumen upgrading is a major source of airborne contaminants such as polycyclic aromatic compounds (PACs). Quantitatively delineating the proportion of petcoke-derived PACs from other potential sources such as unprocessed oil sand, however, is a significant challenge. Previous work on a lake sediment core from the Peace-Athabasca Delta demonstrated the potential of dual $\left(\delta^{13} \mathrm{C}, \delta^{2} \mathrm{H}\right)$ compoundspecific isotope analysis (CSIA) to discriminate PAC sources in the AOSR. In this study, this technique was used to investigate the sources of particulate-bound PACs deposited in AOSR lake snowpack. Higher particulate and PAC loadings, and lower $\delta^{13} \mathrm{C}$ values for phenanthrene and $\mathrm{C}$-alkylated phenanthrenes/anthracenes (C1-Phen) at sites closer to the mining operations indicated that either unprocessed oil sand or petcoke were major sources of anthropogenic fugitive dust. The combined use of $\delta^{13} \mathrm{C}$ and $\delta^{2} \mathrm{H}$ values, however, allowed for further separation of these two sources. Utilising a Bayesian isotopic mixing model, petcoke was quantitatively estimated to comprise between $44-95 \%$ (95\% credibility intervals) of a C1Phen isomer at lakes $<25 \mathrm{~km}$ from the heart of the mining operations, making it by far the most abundant source. This study is the first to demonstrate the potential of CSIA to provide accurate PAC source apportionment in snowpack and reveals that petcoke rather than oil sand is the main source of miningrelated particulate PACs deposited directly to AOSR lakes.
\end{abstract}

